Revista do SELL

v. 6 , no. 2

ISSN: $1983-3873$

\title{
NARRATIVAS CINEMATOGRÁFICAS E IDEOLOGIAS DA CONTEMPORANEIDADE: A EVOLUÇÃO DO FEMININO EM PRODUÇÕES INFANTIS ${ }^{1}$
}

\author{
CINEMATOGRAPHICS NARRATIVES AND CONTEMPORATY IDEOLOGIES: THE \\ EVOLUTIONS OF FEMINISM IN CHILDREN'S PRODUCTIONS
}

\author{
Fernanda Oliveira Santos \\ Universidade Federal de Goiás \\ Silvana Augusta Barbosa Carrijo \\ Universidade Federal de Goiás
}

\begin{abstract}
RESUMO: Neste artigo pretendemos investigar de que forma os filmes Valente (2012), Frozen (2013) e Malévola (2014) concorrem para a formação de novas ideologias no que tange à reconfiguração do feminino examinando o processo de representação identitária das princesas nas narrativas em questão. Observaremos como a arte literária, interligada à arte do cinema, tem se relacionado com a construção da identidade do sujeito, contribuindo para a formação tanto individual quanto coletiva na contemporaneidade. Nos utilizaremos de contribuições advindas de estudos acerca da teoria do cinema, da literatura infantil, dentre outras, para a constituição do instrumental teórico a que recorreremos para compreender a relação da arte literária com a arte cinematográfica.
\end{abstract}

PALAVRAS-CHAVE: literatura; cinema; feminino; subversão.

ABSTRACT: This essay aims to investigate how the movies Brave (2012), Frozen (2013) and Maleficent (2014) contribute to the formation of new ideologies regarding the reconfiguration of the female examining the process of the identity representation of the princesses of the narratives in question. We noticed how the literary art, linked to the art of cinema, has been related to the construction of the subject identity, contributing as the individual formation as the collective in contemporaneity. We are going to use some contribution from film theory academic studies, children's literature, among others, in order to build our theorical background that will help us understand the relationship between these two different arts: literature and cinema.

KEY-WORDS: literature; cinema; female; subversion.

Sabe-se que existe, desde a antiguidade, um desejo latente por parte do ser humano em atribuir sentido à realidade que o circunda. Diante disso, a arte se tornou um dos mecanismos mais utilizados para a concretização desse desejo, permitindo-nos compreender o cinema, que nasce no final do século XIX, como mais um desses mecanismo de significação do real, funcionando como uma possibilidade de representação da condição humana.

\footnotetext{
${ }^{1}$ Trabalho originado do projeto de pesquisa em andamento no Programa de Mestrado em Estudos da Linguagem Unidade Acadêmica Especial em Letras e Linguística. UFG -RC. Instituição fomentadora: CAPES.
} 


\section{Revista do SELL}

v. 6 , no. 2

ISSN: $1983-3873$

Nessa busca pela representação do real, desde o início de sua criação, o cinema vem se inspirando na literatura, compondo, assim, uma interação entre ambas as artes, que enriquecem uma à outra. Com o advento da modernidade, que ocasiona mais acesso às tecnologias e aos meios midiáticos, percebe-se que este processo de hibridização entre tais setores artísticos tem se tornado cada vez mais recorrente, definindo o cinema como sendo um grande contador de histórias da contemporaneidade, seja inspirando-se em histórias clássicas, revisitando-as, ou mesmo criando-as a partir de dadas realidades, conforme observaremos a partir da análise a seguir.

Valente (2012), Frozen (2013) e Malévola (2014) são produções cinematográficas dos estúdios Disney Pictures, líder na indústria de animação para o público infantil, bastante característico por apresentar, na maioria de suas produções, obras que envolvem enredos compostos pela dualidade bem e mal e personagens estereotipadas em narrativas que fornecem uma moral no fim da história. Ao analisar os três objetos fílmicos supracitados, percebemos algumas inovações na estética de sua construção: mudanças de foco no enredo principal e, o que mais nos interessa, a apresentação de personagens femininas que subvertem os padrões tradicionais.

Conforme nosso interesse em observar questões alusivas à construção das princesas em produções do período atual, trouxemos à baila também o filme Valente (2012) que, apesar de não apresentar um diálogo explícito com clássicos da literatura universal, assim como Frozen (2013) e Malévola (2014), muito nos interessa, pois propõe em seu enredo elementos interessantes no que se refere à configuração da imagem da princesa que protagoniza a narrativa. Valente (2012) não alude a um conto de fadas específico da literatura universal, porém, conforme afirma Katherine Sarafian, produtora do filme, a narrativa dialoga com alguns mitos nórdicos do período medieval. Ainda assim, afigura-se relevante ressaltar que a efabulação desta animação revisita as histórias de tempos ancestrais, histórias de batalhas épicas e lendas míticas que passaram de geração para geração nas montanhosas regiões da Escócia, que ao serem transpostas para a linguagem cinematográfica, conferem vida a uma narrativa que subverte padrões de produção, conforme observaremos adiante. 


\section{Revista do SELL \\ v. 6 , no. 2 \\ ISSN: $1983-3873$}

\section{A princesa Valente...}

Coadjuvante de sua própria história, a jovem princesa Merida sempre se identificou mais com o espírito selvagem do pai, assim como às atividades mais comuns ao homens, no contexto do filme, como cavalgar e praticar arco e flecha. Sua aparência física destoa do estereótipo comum do estilo princesa Disney. Merida tem um andar muito mais másculo que delicado, cabelos ruivos que usa sempre soltos - característica que conota sua personalidade forte, desejosa de autonomia. Não lhe agradam os vestidos apertados, fala muito, principalmente sobre o que pensa e sente. Não atribui valor às regras de etiqueta que uma princesa deveria cumprir. Ao contrário, clama por se libertar de padrões.

A jovem apresenta perfil bastante divergente do de sua mãe, uma rainha clássica, que se apresenta sempre impecavelmente arrumada, e que acredita na etiqueta como obrigação social, além do casamento como finalidade única para uma mulher. Merida não compartilha da mesma opinião que a mãe. Recusa-se a se submeter aos desejos da rainha, sendo este o elemento propulsor para todo o conflito que se formará ao longo da história.

A rainha é metamorfoseada em um grande urso selvagem, após a tentativa frustrada de Merida transformá-la, através de um feitiço, em uma pessoa mais flexível. Em decorrência deste acontecimento, tem-se uma mãe tentando civilizar sua própria natureza animal e uma filha que necessita ocultar a nova figura materna do próprio pai, que tem verdadeira aversão por ursos. A metamorfose da rainha confere um tom humorístico à narrativa, ao passo que, mesmo estando no corpo de um urso, ela tenta se manter altiva e elegante. Essa transformação funciona como forma de ressaltar tanto à mãe quanto à filha que as pessoas são diferentes, mas ainda assim precisam se respeitar e se entender.

Decorrente destes elementos conseguimos visualizar indícios de inovação na construção da narrativa fílmica - a família neste caso não aparece mais como uma instituição essencialmente boa e sim como um grupo heterogêneo e conflituoso. Os pais não encerram personagens perfeitas e modelos a serem copiados pelos filhos. Ressaltase a questão das afinidades e o direito de cada um possuir suas próprias opiniões.

A partir da transformação da mãe e da necessidade de mantê-la a salvo cabe à personagem protagonizar a narrativa. Desta feita, Merida deve impedir que seu pai, que desconhece o feitiço, dê fim à rainha, agora incorporada pelo urso. Sendo assim, estamos 


\section{Revista do SELL}

v. 6 , no. 2

ISSN: $1983-3873$

diante de uma personagem principal que não tem um conflito a ser solucionado apenas para si mesma, o que denota mais um caráter inovador na animação, haja vista a recorrência das protagonistas de produções deste gênero em se salvarem e livrarem-se das dificuldades através do amor romântico. Conforme observa Turner

O público identifica-se, voyeuristicamente ${ }^{4}$, com o desejo do herói masculino pela mulher e, narcisisticamente, com a solução ativa que ele impõe à narrativa. Como consequência, as mulheres raramente são essenciais às tramas dos filmes [...], ou representadas como capazes de resolver sozinhas dilemas narrativos (TURNER,1997, p.117).

Em Valente o que observamos contradiz a afirmativa de Turner a respeito da trama fílmica tradicional, ao passo que Merida tanto resolve sozinha os dilemas da narrativa quanto protagoniza toda a história, desconstruindo o conceito de que a mulher, neste caso a princesa, deve esperar pela intervenção de um homem, comumente um príncipe, para livrá-la de todas as dificuldades e lhe conceder a felicidade "para sempre" por meio do casamento.

Momento emblemático na história, que ilustra claramente a subversão da personagem à ideia do matrimônio, dá-se na cena em que Merida concorre à sua própria mão, disputando-a em uma prova de arco e flecha. Para além das habilidades desenvolvidas por uma princesa, a jovem demonstra destreza suficiente para sair vencedora da disputa, conquistando o direito de não se casar. Contrapondo-se ao comportamento das princesas clássicas, Merida se apresenta ousada e autêntica, o que a torna possuidora de uma personagem singular dentre as tantas princesas representadas em animações deste gênero.

Revela-se aqui o que pode ser observado como inovação na forma de representação dos sujeitos sociais na narrativa. Comumente, na maioria das produções clássicas, os sujeitos são representados através dos "papéis" atribuídos às figuras masculinas e femininas. Porém, percebemos que Merida não age em obediência a esses "papéis" que, conforme pondera Guacira Louro

\footnotetext{
${ }^{4}$ As várias categorias em que Freud divide o "olhar" em sua discussão dos componentes da sexualidade humana encontram paralelos nos prazeres que obtemos do cinema. São eles: prazer narcisista (ver a si próprio refletido na tela), voyeurista (apreciar o poder da imagem de outrem na tela) e fetichista (uma maneira de exagerar o poder de coisas materiais ou de pessoas a fim de lidar com o medo que se tem delas). São todas expressões da sexualidade humana, ou deslocamento do desejo; pode-se dizer que todos oferecem meios de identificação entre o filme e o público (TURNER, 1997, p. 116).
} 


\title{
Revista do SELL \\ v. 6 , no. 2 \\ ISSN: $1983-3873$
}

\begin{abstract}
Seriam, basicamente, padrões ou regras arbitrárias que uma sociedade estabelece para seus membros e que definem seus comportamentos, suas roupas, seus modos de se relacionar ou de se portar... Através do aprendizado de papéis, cada um/a deveria conhecer o que é considerado adequado (e inadequado) para um homem ou para uma mulher numa determinada sociedade, e responder a essas expectativas (LOURO, 1997, p. 24).
\end{abstract}

A personagem se recusa a cumprir o papel de princesa justamente por querer fazer suas próprias escolhas, e ser quem realmente é e não o que a sociedade espera que ela seja.

Alguns desses elementos inovadores encontrados em Valente parecem ilustrar não somente uma nova configuração da imagem feminina, mas também o rompimento com tradições sempre recorrentes em produções deste caráter, em que as mulhere são colocadas em condição de assujeitamento aos regimes do maniqueísmo e do patriarcado. Valente revela traços da contemporaneidade que parecem ganhar seu espaço nos roteiros da atualidade, fazendo com que a inserção de uma princesa dotada de características isentas de estereótipos concorra para a disseminação da ideia de mulheres terem liberdade de escolhas tanto sociais quanto individuais. Além disso, devemos considerar que os contos de fadas, sendo eles propagados por meio de narrativas literárias ou fílmicas, auxiliam a criança no processo de descoberta de sua identidade, no modo como elas interagem com o mundo e na sua formação enquanto sujeito social. A disseminação de obras que possuem elementos tais como os que elecamos aqui, notabilizam a existênica de uma gama maior de possibilidades de identificação e construção do imaginário da menina/mulher/princesa.

\section{Do papel à tela: velhas histórias, novas abordagens}

Continuando nossa perspectiva em observar as obras fílmicas em análise uma possível reconfiguração da imagem da mulher, focamos nosso olhar em Frozen (2013), no intento de descobrir se nesta obra, assim como em Valente (2012), existem elementos que nos autorizam compreendê-la como pertencente ao grupo das narrativas cinematográficas que têm se desvencilhado, em alguns aspectos, dos padrões clássicos.

Esta animação dialoga com o livro A Rainha da Neve (1981), de Hans Christian Andersen, apresentando uma intertextualidade direta com este conto, porém não 


\title{
Revista do SELL
}

v. 6 , no. 2

ISSN: $1983-3873$

mimética, devido às inovações e a mudança em vários elementos da narrativa. Também não podemos afirmar que Frozen trata-se exatamente de uma adaptação de $A$ Rainha da Neve, porém, é perceptível que o filme tenha seu roteiro inspirado no conto. Conforme observa Carolina Marinho

\begin{abstract}
É sabido que, desde seus primórdios, o cinema se inspirou na literatura, iniciando, assim, uma parceria afinadíssima que o definiria como o grande contador de histórias do século XX. Por volta de 1908, muitos clássicos da literatura universal foram resgatados para recriar nas telas obras de grande sucesso, responsáveis por uma vertente definitiva que marcaria os novos rumos da história do cinema (MARINHO, 2011, p. 56).
\end{abstract}

Ao observarmos o panorama das produções cinematográficas, percebemos que houve um crescente número de refilmagens, paródias e adaptações. Nas últimas décadas um dos gêneros mais revisitados parece ser o conto de fadas, como já o fez em diversas produções os estúdios Disney, recontando histórias de princesas.

Em Frozen, assim como em Valente, temos um conflito fora da esfera da superação de obstáculos para a realização amorosa entre um príncipe e uma princesa. A narrativa transcorre no limiar do relacionamento entre as irmãs Anna e Elsa, que precisam resolver seus problemas e buscar salvação uma para a outra. Essa parece ser uma ideia anunciada desde o trailer oficial do filme que traz letreiros indagando: "Quem vai salvar o dia? O homem de gelo? O mocinho? O homem de neve? Ou homem nenhum?".

Conforme se anuncia, não há nenhum herói masculino que realizará grandes feitos em razão de salvar alguma princesa indefesa. Ao contrário, os homens da história também subvertem o clássico, compondo personagens como o de Hans, o belo príncipe que nada tem de valente, corajoso ou encantado, não passando apenas de oportunista. $E$ Kristoff, um simples vendedor de gelo, de aparência desprovida de beleza, que ainda assim se tornará o par romântico da princesa Anna.

A narrativa se desenvolve a partir do momento em que Elsa, no dia de sua coroação como rainha, deixa transparecer seus poderes incontroláveis que acaba colocando o reino de Arendelle em um rigoroso e perene inverno. Desta feita tem-se uma princesa, que de certo modo é, ao mesmo tempo, a mocinha e a vilã pois, mesmo que involuntariamente é ela a causadora do grande mal que assola seu reino. Isso faz com que Elsa se recolha ao isolamento, porém longe do castelo onde sempre viveu. Teríamos aqui a representação pela busca de identidade de Elsa que, estando sozinha, poderia 


\section{Revista do SELL}

v. 6 , no. 2

ISSN: $1983-3873$

deixar-se reconhecer não mais repreendendo seus poderes. Conforme podemos observar, é bastante incomum que as princesas procurem autoconhecimento ou revelem seus conflitos pessoais. Contudo, temos uma personagem que, em uma percepção superficial, aparenta ser equilibrada, majestosa e reservada, mas que na realidade vive um conflito interno pelo medo de não saber lidar com o que realmente é.

Apesar de ainda manter presentes alguns elementos bastante recorrentes nas produções Disney, como estereótipo físico da princesa magra, alta, loura e olhos claros, observa-se em Elsa uma figura que rompe com a tradição. Este fato torna-se perceptível pelo modo de ser e agir da personagem, denotando outros referenciais de feminilidade como a coragem e independência, e atitudes de uma mulher que inicia um processo de libertação dos regimes patriarcal e matrimonial, que não se coloca inerte diante de sua condição.

A partir do momento em que Elsa decide viver livre, aceitando lidar com sua magia, temos a conotação da liberdade da força feminina raramente representada em animações deste gênero. Pela primeira vez na idade adulta, Elsa canta, entoando uma canção que soa como um hino de liberdade, pois é concomitante a esse momento que a personagem constroi seu castelo de gelo e se desprende de seu manto de rainha, solta seus cabelos e se desfaz de sua coroa. Todos esses acontecimentos, neste momento da narrativa, simbolizam o processo de libertação dos padrões com os quais Elsa decide se desvencilhar. Desta feita, avistamos uma princesa que transparece autonomia, rompendo o padrão de moças inocentes e passivas, que se colocam inertes às ações praticadas por antagonistas.

Como reflexo do momento histórico em que foram criados, filmes como os que abordamos aqui permitem observar a evolução do comportamento das mulheres. Das donzelas salvas por príncipes à aventureira que não quer se casar. Da princesa reclusa na torre à princesa que constrói seu próprio castelo para descobrir-se a si mesma.

A segunda princesa de Frozen, Anna, aparentemente tem o perfil da princesa clássica, porém, suas características parecem existir muito mais para desconstruir que para reforçar padrões. Anna é apresentada em uma esfera humorística, denotando seu caráter divertido e seu estilo desajeitado. Esse aspecto confere à personagem um rompimento com a visão autoritária das versões tradicionais dos contos de fadas, abrindo espaço para que haja um diálogo entre o que se assiste e às mais variadas realidades do 


\title{
Revista do SELL
}

v. 6 , no. 2

ISSN: $1983-3873$

mundo contemporâneo. Consoante a esse aspecto, temos o envolvimento de Anna com Kristoff, pois a formação deste casal dá-se mesmo após a princesa ter aceitado o pedido de casamento do príncipe Hans. Esse envolvimento ilustra também a subversão à ideia do amor à primeira vista, ilustrando uma história que nasce a partir do convívio entre os dois jovens que despertam sentimentos de admiração que culminam em amor.

Outra demonstração de subversão no filme se dá no momento em que príncipe Hans recusa-se a tentar salvar Anna da morte, concedendo-lhe o beijo do amor verdadeiro, conforme as prerrogativas dos clássicos comuns a este gênero. Assistimos a uma desconstrução da ideia de amor à primeira vista quando Hans revela não amar verdadeiramente a princesa. Esta seria apenas um aporte para Hans tornar-se príncipe de Arendelle.

Observamos até aqui que Frozen renova, ilustra que significativas mudanças estão ocorrendo no mundo das narrativas cinematográficas voltadas para o imaginário infantil. Conforme pondera Burlamaque e Zannata:

\begin{abstract}
Se muitos aspectos mudaram no mundo da fantasia, o que se atrelava ao enredo era seu nível complicado de desenvolvimento, enquanto suas personagens apenas seguiam fielmente o destino reservado a elas de acordo com a trajetória da narrativa. $\mathrm{Na}$ era contemporânea, são as personagens que dão vida e voz ao enredo, tornando-se fundamentais para a existência do mesmo, uma vez que além de conduzirem a história, as personagens rompem a tradição, destacando as jornadas subjetivas que enfrentam rumo ao desfecho da ação (BURLAMAQUE; ZANATA, 2012, p. 89).
\end{abstract}

Em se tratando de narrativas de fadas ou maravilhosas, fazendo uso do meio semiótico legível ou visível, o que podemos observar, comumente, é a recorrência aos padrões. Contudo, as narrativas abordadas aqui nos permitem inferir, através da observação de suas construções, que há mudanças que subvertem os padrões habitualmente seguidos: atos de amor verdadeiro que não se resumem em um mero beijo entre pessoas que se amaram à primeira vista, mulheres protagonizando atos de heroísmo, buscando a solução de seus próprios conflitos, descentralizando o poder patriarcal e falocêntrico. Todos esses elementos tornam-se constituintes de enredos complexos, apresentando problemáticas e ações mais coerentes com a vida e com o cotidiano, rompendo com estereótipos e apresentando uma construção instigante que concilia humor e subversão.

Com o desfecho de Frozen, podemos perceber a existência de elementos que se destacam pelo tom inovador com qual as princesas foram construídas, deixando abertas 


\section{Revista do SELL}

v. 6 , no. 2

ISSN: $1983-3873$

as possibilidades de identificação entre as personagens cinematográficas e as pessoas reais, também dotadas de conflitos internos como angústia, sofrimento e crises de identidade, que passam a ser comuns tanto na realidade quanto na ficção. Esse seria um efeito provocado pelo texto literário que, conforme perspectivas da estética da recepção e seguindo a lógica de Wolfgan Iser, um de seus maiores expoentes, faz com que o receptor adentre na obra e realize inferições. Desta fetia, a obra exerceria efeito sobre seu receptor.

Assim sendo, Elsa e Anna ilustram mais um exemplo de rompimento com o que comumente se apresenta nos contos de fadas. A primeira passa por toda sua trajetória sem esperar por um herói que a livre de seus conflitos e termina a narrativa sozinha sem um par romântico, que confirme a ideia clássica de contrair felicidade apenas por meio do enlace matrimonial. Em contrapartida, o amor acontece para Anna, porém, também desmitificando a ideia do amor à primeira vista e do príncipe como parceiro ideal.

O final da história acontece trazendo à tona a clássica cena do beijo salvador, no entanto, ele é concedido por Elsa à irmã Anna. Não só o beijo, mas o choro pela perda, o abraço que aquece o coração funcionam, nesta narrativa, como conotação do sentimento de fé e amor, representando que a verdadeira magia está na essência de cada ser humano e na sua capacidade de acreditar e amar.

Nessa mesma perspectiva de desconstrução de que somente o amor verdadeiro entre um homem e uma mulher pode funcionar como motivação e salvação para a vida é que encontramos Malévola (2014). Mesmo sendo esta uma obra que revisita o conto clássico da literatura universal, A Bela Adormecida, podemos notar outras mudanças expressivas que subvertem as características dos contos de fadas clássicos.

Ao analisarmos a obra fílmica Malévola temos a percepção de que esta aparece também como uma revisitação da primeira versão criada pelos estúdios Disney de $\mathrm{A}$ Bela Adormecida, lançada em 1959, em que a personagem da bruxa maléfica recebe destaque. Conforme observamos, a recorrência do cinema aos clássicos da literatura universal tem se tornado uma prática comum e, após releituras e refilmagens, temos em Malévola o fenômeno da transtextualidade, conforme nos apresenta Robert Stam em Introdução à teoria do cinema (2003, p. 231): "Tomando como ponto de partida as obras de Bakhtin e Kristeva, Gérard Genette, em Palimpsestes (1982), propôs o termo mais inclusivo "transtextualidade" para referir-se a tudo aquilo que coloca um texto em relação, manifesta ou secreta, com outros textos". 


\section{Revista do SELL}

v. 6 , no. 2

ISSN: $1983-3873$

Conforme o exposto, Malévola nos é apresentado como uma obra que revisita o tradicional conto $A$ Bela Adormecida, porém, inova por não trazer consigo uma repetição da história tradicional. O que nos chama a atenção nesse processo de recriação é o modo como a representação feminina sofre alterações significativas no sentido de demonstrar uma nova configuração para as personagens.

Há em Malévola um enredo principal que não se desenvolve em torno do amor entre a princesa e o príncipe. O foco, desta vez, recai sobre a personagem que dá nome ao filme, Malévola, representando a fada má que lançará a profecia sobre o destino da princesa Aurora, a bela adormecida. Já no início do filme encontramos indícios de que não teremos mais do mesmo já representado até então. A própria personagem de Malévola inicia a narrativa anunciando que será contada "uma velha história de um jeito novo".

Assim como na versão clássica, Malévola é a fada má que lança sobre Aurora o feitiço do sono secular. Porém, vemos nesta versão que a traição de Stefen, pai de Aurora e ex-amor de Malévola, é a motivação para o feitiço vingativo da fada. Esta lança seu feitiço sobre Aurora no intento de agravar a seu pai. Mas o que acontece posposto as este fato é que, ao acompanhar o crescimento da princesa no intento de fazer-lhe o mal, Malévola vai desenvolvendo sentimentos de estima por Aurora.

No momento em que Aurora atinge a adolescência, já se fez amada pela fada antes vingativa que acabou protegendo-a no decorrer de toda sua vida, despertando na jovem princesa a percepção de que Malévola seria sua fada madrinha.

Deste momento em diante nos é revelado um posicionamento inovador por parte da narrativa. A então vilã, passa por um processo de redenção, demonstrando que, a exemplo do que ocorre com as pessoas, ninguém é totalmente bom ou totalmente ruim, conforme durante muito tempo foi rigorosamente representado nos contos de fadas.

Ao cair em sono profundo, conforme a profecia, Aurora só poderá ser salva pelo beijo de amor verdadeiro, que a exemplo de Frozen não partirá do príncipe. Este, mesmo tendo aparecido na história, tem papel irrelevante para o desfecho dos acontecimentos. Por ter se encontrado com Aurora apenas uma vez, não é ele o possuidor do amor verdadeiro pela jovem princesa, logo, não será ele seu salvador nem tampouco partirá dele beijo do amor que libertará Aurora do sono eterno.

É Malévola quem, arrependida por ter lançado o feitiço que levou a princesa ao sono profundo, a beija na face num ato de contrição e amor verdadeiro. É essa atitude de 


\section{Revista do SELL}

v. 6 , no. 2

ISSN: $1983-3873$

sentimento sincero que faz com que Aurora desperte. Nesse sentido, lembremo-nos de Agra Romero (1997), que ressalta podermos observar que os contos literários infantis têm experimentado significativas mudanças de sentido, conforme ocorre com Malévola. Para a autora,

Os contos tal como se coñecían ata o momento son retrógrados, acabando, entre outras cousas, com a submisión da muller e o papel activo do heroe masculino e propondo uma nova temática na literatura fantástica, que segue duas tendencias: A primeira delas [...] considera que os contos tradicionais ensinaban ós/ás nenos/as a adaptar-se ós valores de domínio masculino e submisión feminina, polo que debían ser modificados. A segunda, [...] funde os elementos e temas tradicionais com outros contemporáneos (ROMERO, 1997, p. 223).

Seguindo a perspectiva de Agra Romero, constatamos que as duas tendências constituem uma evolução nos contos de fadas. Elas assinalam para a completude de um círculo na história deste gênero literário, remontando uma nova era dos contos que busca uma maior expressividade da vida comum.

A personagem Malévola, nesta versão fílmica, é demonstrada ao oposto das demais fadas e, apesar de seu próprio nome aludir à "má índole, que é mau ou causa o mal”, esta personagem se difere daquela bruxa completamente má construída no conto clássico, que não reconstrói seus caminhos a partir da mudança de sentimentos ocasionada no decorrer da narrativa. O final, para a bruxa da versão da narrativa literária, continua sendo o clássico. O mal termina mal, recebendo sua punição e vencido pelo bem, conforme pondera Agra Romero (1997) "os personaxens e as figuras dos contos de fadas non son únicos senón típicos, o que possibilita a creación dos denominados <arquetipos> proprios da literatura infantil" (ROMERO, 1997, p. 220. Grifo da autora, tradução nossa).

Dissonante ao tradicional, na versão de Malévola (2014) temos a personagem da fada que assume um estado de maldade. Porém, podemos assistir à transição desse estado para seu sentir original, de benevolência, sem que se percam as características essenciais da personagem.

Ressalte-se que em nenhum momento o estereótipo físico de Malévola, com seus trajes negros, que simbolicamente aludem às trevas, seus chifres, e seu escudeiro, 0 corvo, que numa perspectiva simbológica remete à maldade, impediu que Aurora a 


\section{Revista do SELL}

v. 6 , no. 2

ISSN: $1983-3873$

identificasse como sendo essencialmente boa. Da mesma forma que ocorre com sua personalidade, Malévola traz também em seu estereótipo físico uma dualidade. Apesar de seus trajes e chifres aludirem para o feio, sempre enaltecido na construção física das vilãs clássicas, sua beleza é mantida. Nenhuma referência à clássica bruxa ou, neste caso, fada má. Não há nariz exorbitante, pele enrugada, dentes escuros que remontem um rosto assustador. O rosto da fada é mantido em sua beleza.

Ainda que tenhamos em Aurora o estereótipo físico clássico da princesa alta, magra, e loura, é possível ver em sua essência sentimentos de inquietude que transcendem a passividade da princesa retratada no conto original. Sua atitude, no final da narrativa, em lutar contra seu próprio pai, em favor de sua fada madrinha, demonstram que ela renuncia ao mando patriarcal tão recorrente nos clássicos. Além da negação de Aurora a esse regime, temos a negação de Malévola ao cumprimento de um destino que ela mesma escolheu. A recusa que parte da mudança de sentimentos e, consequentemente de opinião denota o lado mais humanizado da personagem, mais consoante ao poder que cada um possui de lutar em favor do que almeja, não deixando que os acontecimentos se deem simplesmente a cargo do destino.

Talvez essas mudanças estejam concorrendo para a ruptura de personagens estereotipados, valores ultrapassados agregados ao conto de fadas tradicional, seja ele abordado na narrativa literária ou fílmica, sendo que esta última traz consigo ainda a possibilidade de oferecer a seu público a vivência enquanto espectador - levando-o a desfrutar do entretenimento, e personagem - através do qual pode fazer a identificação com as temáticas abordadas. Neste caso, personagens apresentados de maneira instigante, que conciliam menos rigidez e mais subversão, porém ser perder a essência do conto de fadas, oferecem valores que poderão ser utilizados em experiências futuras.

Consoante às considerações de Bruno Bettelheim (1992) é que podemos observar um fundamento na intensa revisitação aos contos da literatura tradicional universal que, mesmo aparecendo com uma estética inovadora, ainda atraem o público, até mesmo para além do universo infantil, justamente por abordarem questões tocantes aos conflitos humanos. Ao serem revisitados ou mesmo criados, os contos tem assumido cada vez mais as características das gerações atuais, principalmente no que se refere à novas posturas sentimentais e de valores pessoais. 


\title{
Revista do SELL
}

v. 6 , no. 2

ISSN: $1983-3873$

\begin{abstract}
Através dos séculos (quando não dos milênios) durante os quais os contos de fadas, sendo recontados, foram-se tornando cada vez mais refinados, e passaram a transmitir ao mesmo tempo significados manifestos e encobertos - passaram a falar simultaneamente a todos os níveis da personalidade humana, comunicando de uma maneira que atinge a mente ingênua da criança tanto quanto do adulto sofisticado. (1992, p.06).
\end{abstract}

Ao serem transpostas para a linguagem cinematográfica, muitas histórias, conforme observamos, têm transformado alguns elementos e agregados outros, o que não as torna melhores ou piores. Do conto clássico da literatura até esta que poderíamos chamar de a última versão fílmica de $A$ Bela Adormecida muitas mudanças podem ser observadas. Personagens que se subvertem, que perdem ou ganham relevância e foco na narrativa, incorporação de novos elementos, acréscimo e mutação de espaço, novos conflitos, tudo isso parece válido no terreno das adaptações. Conforme aponta Stam (2008, p.20)

Uma adaptação é automaticamente diferente e original devido à mudança do meio de comunicação. A passagem de um meio unicamente verbal como o romance para um meio multifacetado como o filme, que pode jogar não somente com palavras (escritas faladas), mas ainda com música, efeitos sonoros e imagens fotográficas animadas, explica a pouca probabilidade de uma fidelidade literal, que sugeriria qualificar até mesmo de indesejável.

Destarte, temos na atualidade uma hibridização de linguagens, transformações e transmutações entre diferentes meios e que se recombinam para que nossas percepções se alterem fazendo com que tenhamos novas apreensões do mundo, nos utilizando também da interface entre cinema e literatura.

A mudança ou reinvenção das histórias e seus personagens denotam a perenidade dos contos de fadas que vão se adaptando para o tempo e espaço atuais, existindo tanto para atender às novas tendências dos meios de comunicação em massa, como o cinema, assim como para o preenchimento de possíveis espaços existentes nas obras originais, agora recontadas sob a luz de outros olhares. Reconfiguradas, adaptadas, recontadas através da narrativa simples ou valendo-se de outros meios, como o cinematográfico, essas histórias continuam contribuindo para a formação do imaginário coletivo, para a propagação dos contos e de toda a significação que eles trazem consigo. 


\section{Revista do SELL}

v. 6 , no. 2

ISSN: $1983-3873$

\section{Considerações finais}

Intentamos, neste artigo, apontar alguns elementos das produções analisas sob a ótica da interface entre literatura e cinema, mais especificamente aos contos de fadas, às histórias de princesas que acenam para mudanças significativas no cenário contemporâneo.

Valente (2012), Frozen (2013) e Malévola (2014), assim como outras obras que não foram contempladas aqui, permitem observarmos que novos olhares têm sido lançados sobre a condição da mulher na sociedade, e novas ideologias estão sendo propagadas. Ideais de príncipes encantados e salvadores, amor à primeira vista e casamento como forma única de felicidade, parecem estar se desfazendo para dar lugar à mulher de personalidade forte, que luta em razão de seus desejos, sua liberdade, seja com arco e flecha ou com as possibilidades de que dispõe. Por trás das conotações, o que se denota é capacidade imbuída à figura feminina de agir por si mesma, de livrar-se do julgo e do mando ao qual foi submetida desde os primórdios das sociedades.

Ainda que tenhamos, nas produções cinematográficas tratadas neste texto, elementos padronizados que não romperam com o clássico, é revigorante saber que grandes meios de comunicação, como os estúdios Disney, têm buscado atualizar o conteúdo de suas produções, que acabam operando como ferramenta de disseminação de ideais e conceitos. Criando ou adaptando, o que temos visto são produções que estabelecem um diálogo mais próximo à realidade, explicitando a existência de relacionamentos dotados de conflitos mas também de sentimentos verdadeiros entre mães e filhas, irmãs e amigas, e a capacidade que as mulheres têm de enfrentar, independentemente, monstros - tanto os fictícios quanto os simbólicos, como crises existenciais.

Diante de todas as reconfigurações às quais temos assistido, não podemos deixar de nos referir ao saldo que tais mudanças deixam para o público masculino, que pode lançar um olhar diferenciado sob as mulheres, enxergando-as como seres humanos independentes e dotados de força. Essa visão possibilita ao público masculino 


\section{Revista do SELL}

v. 6 , no. 2

ISSN: $1983-3873$

desvencilhar-se dos rígidos padrões de masculinidade, contribuindo, desta feita, para as modificações significativas pelas quais as sociedades passam no decorrer do tempo.

Em face do que observamos, podemos afirmar que o resultado dessa hibridização de cinema e literatura tem resultado no que se espera enquanto função social desta última. Concorde às observações de Antônio Cândido (2012), entendemos que a literatura possui função psicológica, e sua produção e fruição se baseiam numa espécie de necessidade universal de fiç̧ão e de fantasia, que de certo modo é coextensiva ao homem, pois aparece invariavelmente em sua vida, como indivíduo e como grupo, ao lado da satisfação das necessidades mais elementares.

\section{Referênicas}

ANDERSEN, Hans Christian. A Rainha da Neve. In Contos de Andersen. 4. ed. Rio de Janeiro: Paz e Terra, 1981, p. 263-299.

BETTELHEIM, Bruno. A psicanálise dos contos de fadas. São Paulo: Paz e Terra, 1992.

BURLAMAQUE, Fabiane Verardi; ZANATTA, Deisi Luzia. Entre cinema e literatura: Rapunzel em nova roupagem. In: Paulo: Cultura Acadêmica, 2012, p. 81-92.

CÂNDIDO, Antônio. A literatura e a formação do homem. 2012. Disponível em: $<$ http://revistas.iel.unicamp.br/index.php/remate/article/viewFile/3560/3007> Acesso em 07 maio 2015.

CUNHA, Carolina. Diretor e produtora de 'Valente' contam como criaram uma princesa cheia de atitude. Saraiva conteúdo/entrevista. 16 nov 2012. Disponível em: <http://www.saraivaconteudo.com.br/Entrevistas/Post/48861> Acesso em: 11 maio 2015.

LOURO, Guacira Lopes. A emergência do gênero. In: (org.). Gênero, sexualidade e educação: uma perspectiva pós estruturalista. Petrópolis, RJ: Vozes, 1997, p. 14-36.

MARTINS, Aracy Alves et al, organizadoras. Livros \& Telas. Belo Horizonte: Editora UFMG, 2011.

ROMERO, Maria Xosé Agra. Corpo de mulher. Discurso, Poder, Cultura. Santiago de Compostela - Galiza, 1997. 


\section{Revista do SELL \\ v. 6 , no. 2 \\ ISSN: $1983-3873$}

STAM, Robert. A literatura através do cinema. Realismo, magia e a arte da adaptação. Belo Horizonte, Editora UFMG, 2008.

STAM, Robert. Introdução à teoria do cinema. Campinas, SP: Papirus, 2003.

TATAR, Maria. A bela Adormecida. In Contos de fadas. Tradução Maria Luiza X. de A. Borges. Rio de Janeiro: Jorge Zahar Editor, 2004, p. 102-108.

TURNER, Graeme. Cinema como prática social. São Paulo: Summus, 1997.

\section{FILMOGRAFIA}

Valente (Brave). Direção: Mark Andrews e Brenda Chapman. Produção: Katherine Sarafian. Disney Pixar Animation Studios, 2012. 93 min.

Malévola (Maleficent). Direção: Robert Stromberg. Produção: Linda Woolverton. Walt Disney Pictures, 2014. $97 \mathrm{~min}$.

Frozen - Uma Aventura Congelante. Direção: Chris Buck, Jennifer Michelle Lee. Produção: Walt Disney Animation Studios, 2013. 102 min. 